\title{
WORKLOAD AND JOB SATISFACTION AMONG GENERAL PRACTITIONERS: A REVIEW OF THE LITERATURE
}

\author{
Peter P. Groenewegen' ${ }^{\prime}$ and JaCK B. F. Hutten ${ }^{2}$ \\ 'Netherlands Institute of Primary Health Care, P.O. Box 1568, 3500 BN Utrecht and \\ ${ }^{2}$ Interuniversity Center for Sociological Theory and Methodology, State University of Utrecht, \\ The Netherlands
}

\begin{abstract}
The workload of general practitioners (GPs) is an important issue in health care systems with capitation payment for GPs services. This article reviews the literature on determinants and consequences of workload and job satisfaction of GPs. Determinants of workload are located on the demand side (list size and composition of the patient population) and the supply side (organization of the practice and personal characteristics of the GP). The effects of workload and job satisfaction on workstyle and quality of work have been reviewed. The length of consultations or booking intervals seems to be an important restriction for workstyle and quality of work.
\end{abstract}

Key words-gencral practice, workload, job satisfaction, quality of care

\section{INTRODUCTION}

There is an ever increasing literature on the correlates of workload of general practitioners (GPs). Most of the literature deals with health care systems with capitation payment for general practitioner services, like in Great Britain and in the Netherlands. One gets the impression that workload is less often perceived as a problem in fee for service systems, where market forces on demand and supply work more strongly than in capitation systems (or salary systems). The policy problem of the justification of income in relation to the amount of workload of GPs seems to be less relevant in fee for service systems. Because of the different problem-context of workload studies in capitation systems like the United Kingdom and the Netherlands and in fee for service systems (in the present review mainly the United States), it may be important to know from what kind of health care system a particular study originates. In the text we have indicated other systems than the U.K. and the Netherlands.

The background to a number of workload studies is the question whether the level of capitation payment justly reflects the amount of work that is generated by different groups of patients [1-3]. Doctors with a comparable list size might have a different workload due to the composition of the practice population.

Another important background to workload studies is the supposed relation between workload and the quality of care of GPs. A high workload might lead to stress and time pressure on the GPs and this in turn might result in shorter consultations, a lower quality of communication between GP and patient, detecting fewer of the patient's problems and generally a lower quality of care [4-9].

Finally, some authors study workload of GPs because of issues in planning and management, such as the ideal size and composition of the primary care team [10], task delegation [11], repeat consultations [11-13] and ideal booking intervals [14].

In this article we review the existing literature on workload, job satisfaction and related issues of general practitioners. Our aim is to sketch an integrated model of the determinants and effects of variations in GPs workload. There are, however, some restrictions. We will not review separate descriptive items, such as the level of the number of consultations in different studies [15]; we are mainly interested in relations, e.g. between list size and the number of consultations per patient. The extensive literature on after-hour calls will not be discussed.

In Section 2 we discuss definitions of workload. The third section describes the relations that have been found between list size, characteristics of the patients on the list and workload. This results in a very simple model in which variations in general practitioner workload are determined only by factors on the demand (or patient) side. In Section 4 the literature on the relations between workload, the ways GPs manage their workload or cope with it and job satisfaction will be reviewed. This results in a somewhat more complicated model that takes into account 'objective' as well as 'subjective' aspects of workload, moderated by the way GPs manage or cope with their workload. Finally, in Section 5 we extend our review to the effects of the before mentioned variables on the workstyle and content of work of general practitioners.

\section{DEFINITIONS OF WORKLOAD}

Undertaking research into the workload of GPs presupposes some definitions and measurement procedures. We distinguish between 'objective' and 'subjective' workload. We will discuss objective workload first. 
Objective workload is generally defined in terms of the amount of time that certain activities consume or the frequency that certain activities take place. The answer to the question which activities to include in definition and measurement of workload depends on what one sees as important aspects of the work of GPs, it depends also on the specific research question and background of the study and of course on the pragmatics of available data and ease of data collection.

In a general sense the work of GPs can be split up into patient related activities and other activities. In an editorial Ball [2] distinguishes between two important aspects of the work of GPs within the patient related activities: cure and care, and adds that quantitative measures of workload are easier for the curative aspects than for the caring aspects. Branthwaite and Ross [16] use more or less the same dimensions: clinical aspects and psychosocial aspects of work. Fleming's report on the Practice Activity Analysis [17] distinguishes two patient related elements of work: patient services (such as repeat prescriptions and telephone calls) and consultations (office visits and home visits), and three groups of other activities: continuing education, health service administration and practice administration.

A study by the DHSS [18] brings in another dimension: the activities while the GP is on duty. While on duty the GP might be involved in patient related activities, in other professional activities such as keeping up with the literature or in non-professional activities. The question is of course how on duty hours have to be counted in studies of workload. The actual measurement of workload is in terms of frequency of activities or the amount of time they take and workload is defined as higher with a greater frequency of activities or with a greater amount of time they take. The next scheme gives an overview of the measures of workload used in empirical studies (the numbers refer to the list of references at the end of this article).

Inclusion of length of consultations and booking intervals in this table might seem a bit strange. The length of consultations could be seen rather as a consequence of workload than as an independent indicator of it. Booking intervals could be seen as a result of decisions to manage workload. However, because in the literature they are used on the same level as the other measures of workload, they are included here. We will come back to this in the fourth section where the ways GPs cope with their workload will be discussed.

The more subjective aspects of workload range from rather direct questions whether physicians feel overworked [19] to measures of job stress $[7,16]$ and job satisfaction [6, 7, 16]. Makin a.o. [7] measure job stress by a 32 item scale developed from interviews with GPs. The items were factor analyzed in four factors: interruptions, emotional involvement, administrative involvement and home/work interface, and routine medical work as sources of job stress. Branthwaite and Ross [16] used 50 items related to sources of satisfaction and pressure, developed from interviews with GPs. The items on sources of pressure cluster in five factors: uncertainty and insecurity, isolation, poor relationships with other doctors, disillusionment in perceived role and awareness of changing demands. The items on sources of satisfaction could be reduced to three factors: psychosocial aspects of work, clinical aspects and management of the practice. Moreover, they used one item to indicate overall satisfaction ('on the whole, I am happy with the work I do").

Apart from job stress, Makin a.o. [7] have also measured job satisfaction with a 9-item Likert scale, previously used in a more extended form in research on other occupational groups, and with a single item measuring overall job satisfaction. Grol a.o. [6] operationalize job satisfaction in terms of how often GPs experience positive or negative emotions with different aspects of their work. They used four positive emotions (contentedness, challenge, selfesteem and well-being) and four negative emotions (lack of time, frustration, tenseness and doubts). They asked GPs 'how often do these feelings occur' when (a) helping patients with diagnosable physical affections; (b) helping patients with psychosomatic complaints and psychosocial problems; and (c) involved in extra activities in addition to consulting hour encounters and home visits? Factor analysis over all emotions and the three aspects of work revealed two factors: positive feelings and negative feelings.

Data collection methods vary from mailed questionnaires where GPs were asked to estimate their workload in terms of hours worked (see e.g. Ref. [4]), to studies where GPs had to record their workload for some time (see e.g. Refs $[1,17]$ and [19] for a combination of a questionnaire and recording in practice), and to studies where an external observer

Table 1. Measures of workload of general practitioners

\begin{tabular}{llc}
\hline Kind of activity & Operational variable & Reference \\
\hline Patient related activities & No. of consultations & $5,10,11$ \\
& No. of visits & 10,11 \\
& No. of consultations per patient & 1,11 \\
& No. of visits per patient & 4,11 \\
& Ratio office consultations/home visits & 4,11 \\
& Hours office consultations & 4 \\
& Hours home visits & 4 \\
& Hours office consultations + home visits & 17 \\
& Hours patient services & 17 \\
& Hours private practice & 17 \\
& Length of consultations & $5,8,14$ \\
& Booking intervals & $4,5,8$ \\
& Hours practice administration & 4,17 \\
& Hours education etc. & 4,17 \\
\hline
\end{tabular}


was used to measure the GP's distribution of time (see Ref, [32]).

\section{LIST SIZE, PATIENTS' CHARACTERISTICS AND WORKLOAD}

The most important article on the relation between list size and workload is Butler and Calnan's 'The economy of time in general practice' [4]. Their point of departure is that 'general practice is demand led'; the workload of GPs is determined mainly by the demand of their patients and the influence of the GP on his own workload is limited. If this line of reasoning which is also at the background of capitation payment of GPs, is true, list size should be the principle determinant of workload:

\section{LIST SIZE $\longrightarrow$ WORKLOAD}

There is indeed a statistically significant relation of list size with different indicators of workload, but correlations are not very strong. Positive correlations have been found with the number of consultations $[5,19]$ and with indicators of number of hours worked $[4,19]$ and in particular the time spend in office consultations. The relatively weak correlations with the number of hours worked indicate deviations from linearity and the influence of other factors on workload.

Negative correlations have been found with the number of consultations per patient and with the length of consultations $[4,5,19-21]$. While GPs with a larger list size spend more time in practice activities, the consultations are generally shorter and the number of consultations and home visits per patient are lower. The variation is higher for GPs with smaller list sizes, suggesting that in these cases other factors also influence the length of consultations and their number per patient; for GPs with larger list sizes the variation within categories of the list size is smaller [19].

The relation between list size and indicators of workload such as the number of hours spend in practice activities is not linear over the whole range of values of list size. The shape of the curve is an inverse $J$, indicating that the workload is not proportionally higher in the higher categories of list size. Interestingly enough the shape of this relation might depend on the system of remuneration. Mechanic [22] in his 1975 study of physicians in fee for service and prepaid primary care settings in the United States, found that prepaid physicians react to a greater number of patients by treating more patients in the same time, while fee for service physicians tend to increase their number of practice hours.

List size is only one indicator for the pressure of demand in general practice. Research into the determinants of utilization of primary medical care [23] suggest that there is a large variation between sociodemographic groups in the use of services and insofar as general practices differ in composition of the patient population this might result in different levels of workload with the same list size. This idea is incorporated in the differential capitation fees in the United Kingdom and has been discussed in The Netherlands where for publicly insured patients a flat capitation fee exists [3].
Apart from list size there are therefore other influences on workload:

\section{LIST SIZE PRACTICE COMPOSITION $\longrightarrow$ WORKLOAD}

Marsh and McNay [10] analyzed the influence of characteristics of the practice population on the workload of GPs. Women have more consultations and home visits, so do young children and the elderly (in particular home visits). Turn-over of the practice population might have a small effect on workload, because newly entered patients consume somewhat more of the GPs time. People with a higher social class background have somewhat more consultations, but lower social class people have somewhat more home visits. Unemployed men consult their doctor more often than employed men; the length of unemployment has no clear linear relationship with consulting a GP, but people who are for five years or more out of work have a higher chance of consulting the GP [24].

Effects on total workload depend of course on the representation of these groups in the practice and on differences between practices in these respects. Wilkin a.o. [19] found no effect on indicators of total workload from the percentage of children aged 0-4 years; a higher percentage of elderly (65 years and older) and of people in social class 1 or 2 was associated with longer hours of work in patient contact. Fleming [1] poses the question whether the existing differentiation in capitation fees in Great Britain justly reflects differences in workload as indicated by the number of consultations per patient. The sex of the patient is the most important determinant of workload. The workload associated with young children and elderly patients is underestimated in the current fee schedule. However, the effects seem to be marginal because practices do not differ greatly in the percentage of women on their list and the higher workload associated with young children is compensated for by a lower workload for children of 5-14 years and men of 24 years and older.

Not only the number of consultations and the time spend in patient contact are influenced by patient characteristics, but also the length of consultations. Morrell [25] found that the length of consultations is influenced by age and social class of the patient, the health problem presented and whether or nol a new problem is presented. Westcott [14] found no difference between consultations with male and female patients, but shorter consultations for patients aged 15-29 years, longer consultations for patients aged 45-64 years and for patients with 'psychoneurotic' problems and a tendency towards shorter consultations with patients from the lower social classes. Andersson and Mattsson [26] in a small study of Swedish salaried GPs report longer consultations for women, elderly patients and patients with psychosocial complaints. Repeat consultations take more time than first consultations. They also report a large amount of variation between GPs, while practice composition did not differ greatly between GPs. "Personal style and different working manners of the 
doctors may thus explain the main reason for this variation" [26, p.132], is their conclusion.

Verhaak [27] studied more than 2500 videotaped consultations and found that consultations of women and older patients last longer. This difference is related to the fact that women and elderly people more often present more than one complaint in the consultation, which corresponds to the findings of Roland and others [8] in the 5 min condition in their study of experimentally manipulated booking intervals. Psychosocial problems and consultations where patient education takes place take more time.

In summary we can state that the workload of GPs is influenced by list size as well as by the characteristics of the practice population served and the health problems presented. As is indicated by the relatively weak correlations demand related factors are not the only determinants of workload in general practice. As will be further explored in the next section workload is not just something that happens to general practitioners, but at least in part it is something that GPs themselves can influence.

\section{WORKLOAD, POSSIBILITIES TO MANAGE WORKLOAD AND JOB SATISFACTION}

The possibilities for managing workload can be divided theoretically into two groups. The first group relates to the organizational aspects of practice, such as single-handed or group practice, the use of a booking system, secretarial support, availability of a practice-nurse or other possibilities to delegate tasks and so on. The second group relates to personal characteristics of the general practitioner. Some of these characteristics may have a direct effect on the objective workload; others on the subjective experience of workload in terms of feelings of overload and job satisfaction. Examples of these personal characteristics are age and experience of the general practitioner, but also aspects of personality and attitudes towards work.

We can therefore extent our simple scheme as follows: strategies' as a consequence of workload in terms of workstyle, having a feedback effect on initial workload. This will be discussed in Section 5.

\section{Practice organization}

As far as the organizational conditions of practice are concerned Wilkin [19] found that single handed practices have a higher workload in the sense that they have a higher average consultation ratio and a longer average consultation time (but there is no significant difference in other indicators of workload such as number of consultations per week, time in surgery and time in patient contact). Practices employing a nurse have a significantly higher workload on all indicators except for the average length of consultations. However, the question of cause and effect is in place here, because a Dutch study [28] of task delegation to a practice secretary (not even a registered nurse) has already indicated a substantial potential time gain. Having an appointment system (which almost all general practitioners have) coincides only with longer consultation time. It should be mentioned that these are the result of bivariate comparisons; the influence of list size and practice composition has not been controlled for.

Appointment systems and an organization of deputizing services are more often found in practices with a larger list size [29]. In group practices the appointment system through a practice receptionist will to a certain extent level out differences in initially demand related workload between partners [30]. Bridgstock [29] also found that appointment systems make it possible to spend more time per consultation, without, however, increasing the (estimated) total number of hours worked. Empirical work showing the extent of task delegation and its relation on the one hand with characteristics of practice organization and scalc and workload on the other hand is scarce (apart from the literature on nurse practitioners in the United States) [31]. The research of Breslau and others [31] in 70 primary care teams in the United States indicates that the extent of task delegation (patientcare tasks: history taking, physical exam, treatment

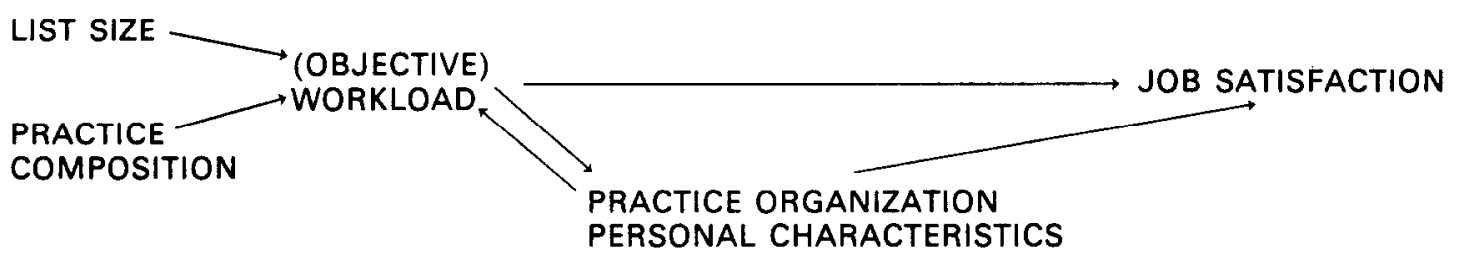

In this section we will review the literature on the relations between (objective) workload, practice organization and personal characteristics (the possibilities to manage workload) and job satisfaction.

Apart from the organizational conditions and personal characteristics workload also depends on the workstyle of general practitioners in the consultation room. General practitioners can manage their workload by using different strategies to end consultations, indirectly by their way of communicating with patients and more directly by proposing a repeat consultation, referring the patient or giving a prescription. We will conceptualize these 'management management and follow-up; technical routinized tasks: weighing and measuring) is greater for technical, routinized tasks and is greater in modern practice settings. Modern practice settings are defined as primary care teams that are organized as part of larger organizations as opposed to traditional teams that are independent single handed or group practices. In traditional teams the amount of delegation of patient care tasks is related to physician' attitudes and the ratio of physicians to paramedics, while the extent of delegation of technical routinized tasks is related only to the level of skills of the paramedics. Delegation in modern practice settings could not be 
predicted from these variables. Dutch research [28] shows that the acceptance of delegation by patients is higher for the more technically oriented aspects of the task of GPs.

Although the evidence is very scattered, the conclusion of Branthwaite and Ross [16] could be retained as a hypothesis that practice organization in the form of larger partnerships makes it possible to structure the workload.

\section{Personal characteristics}

As far as the relations between personal characteristics and workload are concerned, Wilkin a.o [19] found that female GPs have less consultations, spend less time in practice and in direct patient contact. They also found that female GPs show less feelings of being overworked. But this can be a consequence of the fact that women have significant smaller personal list size than men [19]. Wilkin [19] found no relation between the age of GPs and their workload. The study of Armstrong o.a. [21] showed also that, although younger GPs have smaller list size than older GPs, age has no influence on the number of consultations and the number of home visits. Boots [32], however, found that more experienced (and thus on the average older) GPs spend less time on diagnostic aspects of their work and more on advising and counseling their patients.

Calnan [33] investigated the relation between the work orientation of GPs and their workload. More medically oriented GPs (as opposed to more socially oriented GPs) have a higher workload in terms of hours worked. And Branthwaite and Ross [16] found that a higher satisfaction with the clinical aspects of work coincides with more hours in consultations. The more socially oriented GPs in Calnan's study have larger consultation times. This finding is consistent with Verhaak's finding [27] that the personal communication style of GPs influences the length of consultations. An open style of communication (which is characteristic of general practice oriented GPs as opposed to clinically oriented GPsa distinction very close to Calnan's) results in longer consultations, partly because patients have the opportunity to express more complaints in general and more psycho-social complaints in particular. Boots [32] distinguishes between GPs with a broader task perception and those with a smaller which is also close to Calnan's and Verhaak's distinctions. He found that the allocation of time of GPs with a broader task perception is less influenced by the pressure of the number of patients the GP sees per day.

\section{Job satisfaction}

The relations between workload and job satisfaction, and between practice organization and personal characteristics and job satisfaction have not been extensively studied. Calnan [33] found that the more socially oriented GPs have a higher job satisfaction. Although Makin [7] did not directly study the relations between workload and job satisfaction, their findings are indicative in this field. They found that the most important sources of stress in GPs are: interruptions of the daily routine, emotional involvement, administrative workload, and routine work. These sources of stress (except for routine work) are negatively related to overall satisfaction.

McCranie [34] conclude that, on the whole, the family physicians in their study in the United States were very satisfied with their work and careers. Reasons for relative dissatisfaction were: time pressure in practice, the treatment of emotional problems beyond their training, financial costs of their practice, the paper work and perceived interference of external regulations in the patient-physician relationship. Problems related to workload, as time pressure and the amount of paper work, where more mentioned by family phycians who had been in practice for a longer time and those who worked in solo-practices. Mawardi [35], also in a U.S. study, states that time, the lack of leisure time and time pressures of work, present the biggest source of stress in medical practice.

In a pilot study by Rankin a.o. [36] the emotional state of GPs was recorded hourly. The main cause of dissatisfaction was the uncertain state of the work: the factors of hassle and lack of time together accounted for more than the half of the reasons given for a drop in mood. Furthermore their results suggest that GPs get the most pleasure in the work for which they are trained and less pleasure in dealing with social problems which may take a long time and have unsatisfactory outcomes.

Breslau [37] argue that varied and complex tasks will lead to greater job satisfaction than routine and repetitive tasks. That can be seen as an explanation for their finding that primary care physicians in modern organizational work settings in the U.S. had a lower satisfaction with the work activity, with coworkers and with income, than in more traditional office practices.

In conclusion we can say that the relations between (objective) workload, possibilities to manage workload, and job satisfaction have not been studied systematically and as conclusive as the more simple relations between list size and practice composition, and workload. Practice organization (partnership, appointment system, delegation) seems to be a way to manage workload and as part of the coping possibil. ities of GPs might be hypothesized also to influence the relation between (objective) workload and job satisfaction. As far as personal characteristics are concerned the work orientations or task perceptions of GPs seem to be an important issuc because they relate both to the allocation of time in general practice and to job satisfaction. Work orientation or task perception might be the more important because it is also one of the determinants of work style and possibly through the feedback of workstyle on (objective) workload.

Combining the insights from Section 3 on the influence of demand characteristics on workload and from this section on the influence that the general practitioner himself can exert on his workload, a more theoretical distinction in the work and workload of GPs might be the distinction between that part of the workload that the GP has no influence on and the part that is influenced by the GP [33]. 


\section{EFFECTS ON WORKSTYLE}

Part of why workload and job satisfaction is an important topic in health services research is that given levels of workload and job satisfaction might affect the workstyle of general practitioners and the quality of their work. On the other hand aspects of workstyle are closely interrelated with the way GPs manage their workload and with the GP or supply induced workload itself. Relevant aspects of workstyle are: the kind of interventions that take place in consultations (e.g. doctors who do a lot of minor surgery themselves vs those who do not), the communication style of the GP, referrals, prescriptions and repeat consultations. In this part of the review our emphasis is not on explaining differences in e.g. referral rates between GPs; we only look at these aspects of workstyle as far as they are part of a more or less integrated model of workload and job satisfaction. The analytical scheme developed throughout this review can now be extended with workstyle: often prescribe drugs without actual face to face contact with patient [39].

The findings of Melville are only partially confirmed by Haaijer's study of prescribing in general practice [40]. GPs' satisfaction with their work (measured and analyzed as four separate items) did not relate to the volume and cost of prescribing, but one of the items-the estimate of the percentage of patients presenting trivial complaints-did relate to a lower quality of prescribing.

Apart from this research on the direct relationship between job satisfaction and workstyle, there is research on the relationship between workload and work style, cspccially on length of consultation and workstyle. In 'the $5 \mathrm{~min}$ consultation' Roland [8] experimentally manipulated the booking intervals of five GPs in one group practice. The three conditions were booking intervals of $5,7 \frac{1}{2}$ and $10 \mathrm{~min}$. The 5 min condition resulted in shorter consultations. The effects on work style are in the number of problems in general and psychosocial problems in particular

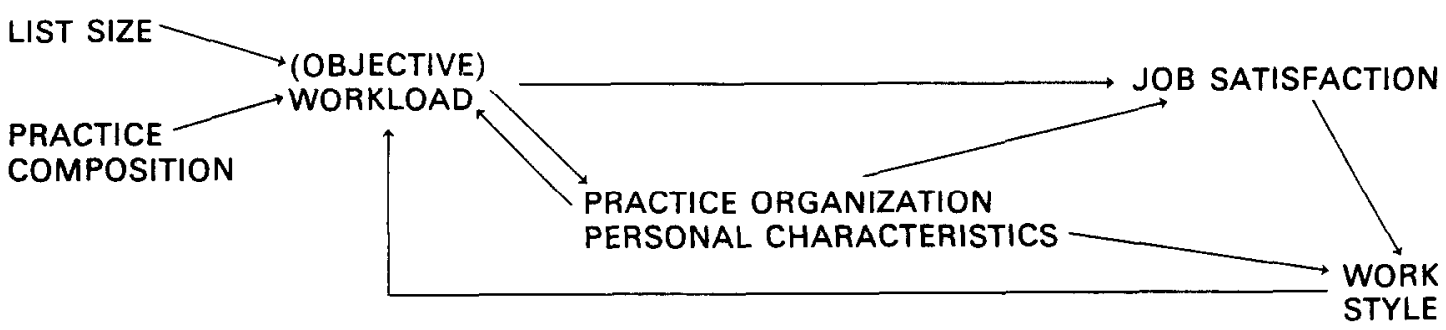

We have found only two references to research that investigates the relation between job satisfaction and workstyle.

The relation between job satisfaction and workstyle in general has been investigated by Grol [6]. They have looked at the quality of care as exemplified by prescriptions, referrals, the medical aspects of care and the psycho-social aspects of care. They used both administrative data (on referrals and prescriptions) and direct observation according to a protocol (medical and psycho-social aspects of care). Satisfaction was measured in terms of positive and negative feelings (see Section 2). Positive feelings of the GP coincide with a more open communication style and more attention to psychosocial aspects of the complaints of the patients, but also with a higher number of referrals. Negative feelings coincide with more prescriptions and less explanation to the patient.

Melville [38] has investigated the relation between job satisfaction and the quality of prescribing. Job satisfaction was measured with a five item Likert type scale (Cronbach's alpha 0.92). The quality of prescribing was measured by looking at six groups of drugs that were under debate at the time, either because of serious adverse reactions or possible interactions or because of the risk of addiction or dependency. It turned out that the hypothesis that GPs with lower levels of job satisfaction have a lower quality of prescribing, was confirmed for four out of six groups of drugs, while in two cases there was no significant relationship. Another interesting finding was that GPs with lower levels of satisfaction more that were detected by the GP. Contrary to the authors' expectations there was no difference between the conditions in the field of prescriptions, examinations, referrals and repeat consultations. GPs were not more stressed, but patients were less satisfied in the $5 \mathrm{~min}$ condition. A replication of this study [9] only showed improved communication (GPs spent more time in explaining the problem to the patients) and higher patient satisfaction in the condition of longer booking intervals.

These results are supported by a study by Howie and his colleagues $[41,42]$. In 'measurement of stress as it affects the work of the general practitioner' [42] they put forward two hypotheses: The first is that doctors behave differently when surgery workload and other loads reach a level which causes tension or strain; the second is that 'pressured' behavior from the doctor is less satisfying to the patient, less effective clinically and more costly in terms of referrals and prescriptions. Until now only the first results of their project have been published and the hypotheses have not yet been fully tested. What they did find [41] was a relation between the average length of consultations and the handling of psychosocial problems. GPs were categorized as 'fast', 'intermediate' or 'slow' on the basis of a recording of the time they spent in all consultations. The effects on workstyle were investigated for consultations with patients with respiratory illness. Aspects of workstyle investigated were the extent to which psychosocial problems were explored and the prescription of antibiotics. They found no difference between the three groups in the detection of psychosocial problems. There was, however, a 
difference between GPs who usually have short or intermediate consultations on the one hand and those with usually long consultations on the other hand. The latter GPs more often explore the psychosocial problems to a greater extent. No direct relation with the prescription of antibiotics was found.

Hartzema and Christensen [43], in a study in the U.S., found that one of the nonmedical factors associated with prescribing volume is the number of patients processed per clinic hour in a primary care HMO setting.

In an older study in Aberdeen, Richardson [44] found a positive relation between consultation rate and the rate of repeat consultations. Therefore they conclude that GPs can influence their workload, because repeat consultations are substantially under the doctors own control.

Practice organization and personal characteristics of GPs relate to aspects of workstyle. GPs with a gencral practice orientation, as opposed to a clinical orientation, have a more open style of communication [27].

GPs in partnerships and especially in health centres refer less patients $[45,46]$; so do GPs with a broader task perception [47]. The relation between list size and referral rate is ambiguous, presumably because of the separate relations between list size and consultation rate, and consultation rate and referral rate [48]. Wilkin and Smith [49] in their review of the literature conclude that the evidence on list size provides little support for the view that high referral rates might result from pressure of work. Boots [32] in his time study of general practice even found that a smaller number of patients per unit of time coincided with more referrals.

Haaijer's summary of the literature on the relation between list size and prescribing in general practice [40] confirms the conclusion of Wilkin and Smith on referrals. In her empirical analyses she did not find any clear relations either

Summarising this section, we can say that studies, explicitly devoted to the analysis of the effects of workload (or indirect indicators of workload, like list size) and job satisfaction on workstyle and quality of work are scarce. Moreover, the studies on job satisfaction and quality of work only look at part of the model we have developed in the course of this review. For this reason as well as given the actual findings in these studies, no firm conclusions can be drawn, although there are indications of a positive relation of satisfaction and quality of work. The quality of the doctor-patient relationship also seems to be affected by workload. Longer consultations give more room to the patients and lead to higher patient satisfaction. In the broader literature on aspects of workstyle, such as communication style, referrals and prescriptions, workload is only one out of many possibly influencing variables. It is difficult to isolate the influence of workload or workload related variables in these studies.

\section{CONCLUSIONS}

We have organized the literature in this review around increasingly complex analytical models of the determinants and effects of GPs' workload. Starting with the relation between list size and workload, we have subsequently extended the discussion with the influence of differences in the composition of the GPs' practices. Together list size and practice composition indicate the demand led part of workload. It is important to distinguish this demand led part of workload from the part that is influenced by the GP him/herself. This distinction has to be taken into account in the measurement of aspects of workload by dividing consultations or visits according to the initiative for the contact, the patient or the GP. First contacts in an episode of care could be defined as patient initiated and repeat consultations as physician initiated. This distinction presupposses data collection at the level of contacts or episodes of care through a recording of activities in general practice. But these kind of studies are seldomly done on a large enough scale to enable elaborate multivariate analyses of the interrelations between the variables in the more complex models.

The more complex models look at the relations between workload and job satisfaction or the subjective experience of workload and the possibilities to manage workload. These relations have not been studied systematically. Practice organization seems to have a relation to the possibilities to manage workload. Work orientation or task perception might be as important. The attempts of GPs to manage their workload might become visible in the length of consultations. Length of consultation is on the one hand influenced by the pressure of patient initiated demand and by the management decisions of the GP (e.g. in setting booking intervals) and on the other hand the length of consultation could be seen as a restriction on the GPs' possibilities to exert a certain style of practice and to reach standards of quality.

Work style is affected by workload through the restrictions of time, but at the same time influences workload through the decisions to explore deeper the patient's problems or to end the consultation with a referral or prescription. Although these mutually influencing relations can be distinguished analytically, it is very difficult to analyse them empirically

As was already mentioned in the introduction, workload is mainly an issue in health care systems with capitation payment for GPs' services. The question is whether GPs' reactions to workload differ according to the system of professional reimbursement. The relations between list size and number of hours worked (weakly positive) and consultation rate and length of consultation (weakly ncgativc) suggest that in capitation systems larger list size or higher patient load coincide with GPs 'processing' more patients per unit of time. Mechanic's study [22] which compares capitation and fee for service, shows a different reaction to workload in fee for service systems: higher patient load coincides with more hours of work at constant length of consultations. One could add to this a hypothesis on salaried systems. Because in salaried systems the number of hours worked is fixed by contract and there is no competition for patients (as there is at least to some extent in capitation systems and to a large extent in fee for service systems), one would expect to find increases of waiting lists as a typical reaction to higher patient load in salaried systems. These, 
hypothetical, different reactions to workload warrant further study of workload under different conditions of remuneration.

\section{REFERENCES}

1. Fleming D. M. The case for differential capitation fees based on age in British general practice. Br. Med.J. 297, 966-968, 1988.

2. Ball J. G. Workload in general practice. Br. Med. J. 277, 868-870, 1978.

3. Wal G. van der Voor een differentiering binnen het abonnementshonorarium. Huisarts en Wetenschap. 27, suppl., 68-71, 1984.

4. Calnan M. and Butler J. R. The economy of time in general practice: an assessment of the influence of list size. Soc. Sci. Med. 26, 435-441, 1988.

5. Knight $R$. The importance of list size and consultation length as factors in general practice. $J$. R. College gen. Practitioners 37, 19-22, 1987.

6. Grol R., Mokkink H., Smits A. Work satisfaction of general practitioners and the quality of patient care. Family Practice 2, 128-135, 1985.

7. Makin P. J., Rout U. and Cooper C. L. Job satisfaction and occupational stress among general practitioners; a pilot study. J. R. College gen. Practitioners 38, 303-306, 1988.

8. Roland M. O., Bartholomew J., Courtenay M. J. F. The 'five minute' consultation: effect of time constraint on verbal communication. Br. Med. J. 292, 874-876, 1986.

9. Ridsdale L., Carruthers M., Morris R. and Ridsdale J. Study of the effect of time availability on the consultation. J. R. College gen. Practitioners 39, 488-491, 1989.

10. Marsh G. N. and McNay R. A. Factors affecting workload in general practice-II. Br. Med. J. 269, 319-321, 1974.

11. Marsh G. N. and McNay R. A. Team workload in an English general practice-I. Br. Med. J. 269, 315-318, 1974.

12. Carney T. A. A comparison of workload and morbidity recording by partners in a group practice. $J$. R. College gen. Practitioners 30, 271-277, 1980

13. Carney T. A. Characteristics of general practitioners with high and low recall rates. Family Practice 4, 183-191, 1987.

14. Westcott $R$. The length of consultations in general practice. J. R. College gen. Practitioners 27, 552-555, 1977.

15. Thomas K., Birch S., Milner P., Nicholl J., Westlake L. and Williams B. Estimates of general practitioners workload: a review. J. R. College gen. Practitioners 39, 509-513, 1989.

16. Branthwaite A. and Ross A. Satisfaction and jobstress in general practice. Family Practice 5, 83-93, 1988.

17. Fleming D. M. Workload review. J.R. College gen. Practitioners 32, 292-297, 1982.

18. Department of Health and Social Security (1987). See also the comments to this study on the implications for remuneration by Ridsdale L. General practitioner workload: research and policy. J. R. College gen. Practitioners 38, 390-391, 1988.

19. Wilkin D., Hodgkin P. and Metcalfe D. Factors affecting workload: is received wisdom true? In The Medical Annual, 1986. The Yearbook of General Practice (Edited by Pereira Gray D. J.). Wright, Bristol, 1986.

20. Fleming D. M. Consultation length (letter to the editor), J. Royal College gen. Practitioners 37, 179, 1987.

21. Armstrong D. and Griffin G. A. Patterns of work in general practice in the Bromley Health District. $J$. $R$. College gen. Practitioners 37, 264-266, 1987.

22. Mechanic $D$. The organization of medical practice and practice orientations among physicians in prepaid and non-prepaid primary care settings. Med. Care 13, 189-204, 1975.

23. Muller C. Review of twenty years of research on medical care utilization. Hlth Services Res. 21, 129-144. 1989.

24. Yuen $P$. and Balarajan $R$. Unemployment and patterns of consultations. Br. Med. J. 298, 1212-1214, 1989.

25. Morrell D. C., Evans M. E., Morris R. W. and Roland $M$. O. The 'five minute' consultation: effect of time constraint on clinical content and patient satisfaction. Br. Med. J. 292, 870-873, 1986

26. Andersson S-O. and Mattsson B. Length of consultations in general practice in Sweden: views of doctors and patients. Family Practice 6, 130-134, 1989.

27. Verhaak P. F. M. Bewerkelijkheid van huisartsconsulten met verschillende klachten of patiënten, uitgedrukt in tijd. Tijdschrift voor Sociale Gezondheidszorg 64, 558-562, 1986.

28. De Haan J. De doktersassistente; Delegeren van taken in een Huisartspraktijk. Lelystad, Meditekst, 1986.

29. Bridgstock M. General practitioners' organization and estimates of their workload. J. R. College gen. Practitioners 26, suppl. 1, 16-24, 1976.

30. Freeman G. K. Receptionists, appointment systems and continuity of care. I. R. College gen. Practitioners 39, $145-147,1989$

31. Breslau N., Wolf G., Novack A. H. Correlates of physician' task delegation in primary care. J. Hlth soc. Behav. 19, 374-384, 1978.

32. Boots J. M. J. Het werk van de huisarts: resultaten van een functie analyse in 93 huisartspraktijken. Maastricht, Rijksuniversiteit Limburg, 1983.

33. Calnan M. Images of general practice: the perceptions of the doctor. Soc. Sci. Med. 27, 579-586, 1988.

34. McCranie E. W., Hornsby J. L. and Calvert J. C. Practice and career satisfaction among residency trained family physicians: a national survey. J. Family Practice 14, 1107-1114, 1982.

35. Mawardi B. H. Satisfaction, dissatisfaction, and causes of stress in medical practice. JAMA 241, 1483-1486, 1979.

36. Rankin H. J., Serieys N. M. and Elliot-Binns C. P. Determinants of mood in general practitioners. $\mathrm{Br}$. Med. J. 294, 618-620, 1987

37. Breslau N., Novack A. H. and Wolf G. Working settings and job satisfaction: a study of primary care physicians and paramedical personnel. Med. Care 16, $850-862,1978$.

38. Melville A. Job satisfaction in general practice: implications for prescribing. Soc. Sci. Med. 14A, 495-499, 1980.

39. Furthermore, there is some but not very strong evidence that face to face consultations lead to less prescribing compared to indirect consultations; compare HaaijerRuskamp F. M., Stewart R. and Wesseling H. Does indirect consultation lead to overprescribing in general practice? Soc. Sci. Med. 25, 43-46, 1987.

40. Haaijer-Ruskamp F. M. Het voorschrijfgedrag van de huisarts. Thesis, University of Groningen, 1984.

41. Howie J. G. R., Porter A. M. D. and Forbes J. F. Quality and the use of time in general practice: widening the discussion. Br. Med. J. 298, 1008-1010, 1989.

42. Porter A. M. D., Howie J. G. R. and Levinson A. Measurement of stress as it affects the work of the general practitioner, Family Practice 2, 136-146, 1985.

43. Hartzema A. G. and Christensen D. B. Nonmedical factors associated with the prescribing volume among family practitioners in an HMO. Med. Care 21, 990-1000, 1983.

44. Richardson I. M., Howie J. G. R., Durno D. A study of general practitioner consultations in Northeast Scotland. J. R. College gen. Practitioners 23, 132-142, 1973. 
45. Wijkel D. Lower referral rates for integrated health centres in the Netherlands. Hlth Policy 6, 185-198, 1989.

46. Wijkel D. Encouraging the development of integrated health centres: a critical analysis of lower referral rates, Soc. Sci. Med. 23, 35-41, 1986.

47. Dopheide J. P. Verwijzingen door de huisarts: enkele determinanten van het verwijscijfer van solo-huisartsen op het verstedelijkt platteland en in forensengemeenten. Gezondheid Samenleving 3, 141-151, 1982.

48. Posthuma B. H. and van der Zee J. Tussen eerste en tweede lijn, deel II: over praktijkgrootte en productiecijfers van huisartsen, Utrecht, NHI, 1978.

49. Wilkin D. and Smith A. Explaining variation in general practitioner refferals to hospital. Family Practice 4, 160-169, 1987. 